dictive value of the rectal swab suggests that patients who are not colonized in the gastrointestinal tract are at low risk for subsequent infection. However, in a population with a low prevalence of $A$ baumanii infection (20/751, 2.7\%), rectal swab is useless for detecting patients with $A$ baumanii infection in view of its low positive predictive value. This contrasts with other results that suggested that gastrointestinal tract colonization frequently was present before, or at the time of, infection by $A$ baumanii. ${ }^{6}$ Interestingly, our results suggest that the detection rate of rectal swabs was higher for patients who had a longer stay in the ICU.

To evaluate whether sampling other sites improved the colonization detection rate, we analyzed a subgroup of infected or colonized patients and found no significant differences between rectal, nasal, or groin colonization $(60 \%, 56 \%$, and $52 \%$, respectively). Previous studies evaluating the relation between colonization and infection have reported conflicting results, varying from no positive rectal swabs in patients from whom the epidemic strain already had been isolated ${ }^{11}$ to a high positivity rate of nasal swabs during a hospital outbreak. ${ }^{7}$ In contrast with our data, a recent report found that clinical infections occurred more frequently in patients with fecal colonization than in those without fecal colonization. 10 However, in that study, performed during two different 2month periods in 189 consecutive patients in ICUs, the percentage of patients with fecal colonization was much higher (41\%) than in our study (8.7\%), which was performed during 8 consecutive months in 751 consecutive patients.

We found that a combination of rectal and nasal swabs improved the detection rate in the present study; adding groin culture did not provide any additional information. The previously reported high mortality and morbidity rates associated with infection and colonization by $A$ baumanii in ICU patients ${ }^{4}$ suggest that improvements in preventive measures, including usual isolation procedures or ancillary supportive care, will be needed based on early detection of colonized patients.
96-CC-142. Address reprint requests to Jean-Yves Fagon, MD, Service de Réanimation Medicale, Hôpital Broussais, 96 rue Didot, 75014, Paris, France.

\section{REFERENCES}

1. Bergogne-Berezin E, Joly-Guillou ML, Vieu JF. Epidemiology of nosocomial infections due to Acinetobacter calcoaceticus. J Hosp Infect 1987;10:105-113.

2. Beck-Sague CM, Jarvis WR, Brook JH, Culver DH, Potts A, Gay E, et al. Epidemic bacteremia due to Acinetobacter baumanii in five intensive care units. Am J Epidemiol 1990;132:723-733.

3. Hartstein AI, Rashad AL, Liebler JM, Actis LA, Freeman J, Rourke JW, et al. Multiple intensive care unit outbreak of Acinetobacter calcoaceticus subspecies anitratus respiratory infection and colonization associated with contaminated, reusable ventilator circuits and resuscitation bags. Am J Med 1988;85:624-631.

4. Lortholary O, Fagon JY, Buu Hoi A, Slama MA, Pierre J, Giral $\mathrm{P}$, et al. Nosocomial acquisition of multiresistant Acinetobacter baumanii: risk factors and prognosis. Clin Infect Dis 1995;20:790-796.

5. Fujita K, Lilly HA, Aycliffe GAJ. Spread of resistant gram-negative bacilli in a burns unit. J Hosp Infect 1982;3:29-37.

6. Timsit JF, Garrait V, Misset B, Goldstein FW, Renaud B, Carlet $\mathrm{J}$. The digestive tract is a major site for Acinetobacter baumanii colonization in intensive care unit patients. J Infect Dis 1993;168:1336-1337.

7. Allen KD, Green HT. Hospital outbreak of multi-resistant Acinetobacter anitratus: an airborne mode of spread? J Hosp Infect 1987;9:110-119.

8. Sakata H, Fujita K, Maruyama S, Kakehashi H, Mori Y, Yoshioka H. Acinetobacter calcoaceticus biovar anitratus septicaemia in a neonatal intensive care unit: epidemiology and control. J Hosp Infect 1989;14:15-22.

9. Wise KA, Tosolini FA. Epidemiological surveillance of Acinetobacter species. J Hosp Infect 1990;16:319-329.

10. Corbella X, Pujol M, Ayats J, Sendra M, Ardanuy C, Dominguez MA, et al. Relevance of digestive tract colonization in the epidemiology of nosocomial infections due to multiresistant Acinetobacter baumanii. Clin Infect Dis 1996;23:329-334.

11. French GL, Casewell MW, Roncoroni AJ, Knight S, Phillips I. A hospital outbreak of antibiotic-resistant Acinetobacter anitratus: epidemiology and control. J Hosp Infect 1980;1:125-131.

\title{
CDC's Immunization Practices Advisory Committee Revises Vaccine Recommendations for HCWs
}

\section{Gina Pugliese, RN, MS Martin S. Favero, $\mathrm{PhD}$}

The CDC's Immunization Practices Advisory Committee recently issued updated recommendations on immunization of healthcare workers. These new guidelines update previous recommendations, published in
1987 and revised in 1989, and will be consistent with the immunization recommendations from the CDC's Hospital Infection Control Practices Advisory Committee's soon-to-be released "Guideline for Infection Control in Health Care Personnel."

These guidelines contain background information for each vaccine- preventable disease with specific recommendations for use. A copy of this document can be obtained from the CDC's web site at http://www.cdc. gov/epo/mmwr.

FROM: Centers for Disease Control and Prevention. Immunization recommendations for health care workers. MMWR 1997;46(RR-18):1-51. 